\title{
Proteomic and metabolomic responses in hepatopancreas of Mytilus galloprovincialis challenged by Micrococcus luteus and Vibrio anguillarum
}

\author{
Huifeng $\mathrm{Wu}^{a, *}$, Chenglong $\mathrm{Ji}^{a, b}$, Lei Wei ${ }^{a, b}$, Jianmin $\mathrm{Zhao}^{a}$, Hongjian $\mathrm{Lu}^{\mathrm{c}}$ \\ ${ }^{\mathrm{a}}$ Key Laboratory of Coastal Zone Environmental Processes, Yantai Institute of Coastal Zone Research (YIC), Chinese Academy of Sciences (CAS), \\ Shandong Provincial Key Laboratory of Coastal Zone Environmental Processes, YICCAS, Yantai 264003, PR China \\ ${ }^{\mathrm{b}}$ The Graduate School of Chinese Academy of Sciences, Beijing 100049, PR China \\ 'Institute of Chemistry and BioMedical Sciences (ICBMS), Nanjing University, Nanjing 210046, PR China
}

\section{A R T I C L E I N F O}

\section{Article history:}

Received 9 July 2013

Accepted 9 September 2013

Available online 20 September 2013

Keywords:

Proteomics

Metabolomics

Mytilus galloprovincialis

Bacteria

\begin{abstract}
A B S T R A C T
The outbreak of pathogens can induce diseases and lead to massive mortalities of aquaculture animals including fish, mollusk and shrimp. In this work, the responses induced by Micrococcus luteus and Vibrio anguillarum were investigated in hepatopancreas of mussel Mytilus galloprovincialis using proteomics and metabolomics. Metabolic biomarkers demonstrated that M. luteus and V. anguillarum injections could induce osmotic stress and disturbance in energy metabolism. And the uniquely and more markedly altered metabolic biomarkers (glutamine, succinate, aspartate, glucose, ATP, homarine and tyrosine) indicated that V. anguillarum could cause more severe disturbances in osmotic regulation and energy metabolism. The differentially altered proteins meant that $M$. luteus and V. anguillarum induced different effects in mussels. However, the common proteomic biomarkers, arginine kinase and small heat shock protein, demonstrated that these two bacteria induced similar effects including oxidative stress and disturbance in energy metabolism in M. galloprovincialis. In addition, some metabolic biomarkers, ATP and glutamine, were confirmed by related proteins including arginine kinase, ATP synthase, nucleoside diphosphate kinase and glutamine synthetase in bacteria-challenged mussels. This study demonstrated that proteomics and metabolomics could provide an insightful view into the effects of environmental pathogens to the marine mussel M. galloprovincialis.
\end{abstract}

\section{Biological significance}

The outbreak of pathogens can lead to diseases and massive mortalities of aquaculture animals including fish, mollusk and shrimp. The mussel M. galloprovincialis distributes widely along the Bohai coast and is popularly consumed as delicious seafood by local residents. This bivalve has become one of the important species in marine aquaculture industry in China. Therefore a study on pathogen-induced effects is necessary. In the present study, an integrated metabolomic and proteomic approach was used to elucidate the differential effects induced by the representative Gram-positive (M. luteus) and Gram-negative (V. anguillarum) bacteria in M. galloprovincialis.

(c) 2013 Elsevier B.V. All rights reserved.

* Corresponding author. Tel.: +86 535 2109190; fax: +86 5352109000.

E-mail address: hfwu@yic.ac.cn (H. Wu). 


\section{Introduction}

The outbreak of pathogen pollutants can lead to significant losses of production for aquaculture industry as pathogens can cause diseases, reduce product quality and lead to massive mortalities of aquaculture animals including fish, mollusk and shrimp [1]. In addition, the consumption of pathogen-infected seafood may cause food poisoning and therefore poses high risk on human health [2]. Among the aquaculture animals, marine bivalves such as scallop Chlamys farreri, clam Ruditapes philippinarum and mussel Mytilus galloprovincialis are of great economic values and widely cultured in China. In different marine bivalves, pathogens (such as vibrios) can usually induce changes in phagocyte activity, increases in hydrolytic enzyme activities and excessive production of reactive oxygen species (ROS) in the soluble hemolymph fraction [3,4]. The mussel M. galloprovincialis distributes widely along the Bohai coast and is popularly consumed as delicious seafood by local residents. Therefore this bivalve has become one of the important species in marine aquaculture industry in China. M. galloprovincialis is a preferable bioindicator for marine environmental contaminants in 'Mussel Watch Program' and frequently investigated as an experimental species in ecotoxicology due to its high accumulation and tolerance to marine environmental contaminants $[5,6]$. In addition, as a filter-feeder, M. galloprovincialis can accumulate a large amount of bacteria from the seawater and therefore has been used in immunity studies of marine aquaculture animals [7]. Traditional approaches in the immune innate system in M. galloprovincialis consist of histological studies on the lesions and the identification and characterization of a certain class of molecules in the immune network at gene and protein levels [7-10]. For example, infection of vibrios (Vibrio splendidus and Vibrio anguillarum) could significantly up-regulated the expression of antioxidant enzymes (catalase and glutathione transferase), lysozymes and metallothioneins which are involved in immune defense systems in M. galloprovincialis [8]. Since researchers basically work on the identification and function characterization of immunerelated molecules using cloning and recombinant technologies, which have few opportunities to discover new molecules related to immunity, these researches obviously presented a primary but comprehensive understanding of immune responses of M. galloprovincialis to pathogen challenges.

With the emergence and development of system biology techniques, including genomics, transcriptomics, proteomics and metabolomics, have offered great potential in unraveling biological problems and have been successfully employed in multiple areas such as environmental sciences, drug discovery and immunology [11-13]. Among these approaches, proteomics can theoretically present all the proteins encoded by the given genome in an organism [14]. The two-dimensional electrophoresis (2-DE)-based proteomics remains widely useful to characterize complex biologically functional protein networks [15]. Not only can proteomics describe a complete proteome at organelle, cell, or tissue levels, but it can also compare proteomes and then detect proteomic differences caused by either biotic or abiotic stressors [16]. Metabolomics usually focuses on the whole set of low molecular weight $(<1000 \mathrm{Da})$ metabolites that are the end products in various biological systems including organs, tissues, biofluids, or even whole organisms $[17,18]$. Similar to proteomics, a comparative profiling of metabolomes can give metabolic responses induced by exogenous factors in organisms $[19,20]$. Since proteomics and metabolomics may characterize the perturbations in metabolites and proteins involved in the same metabolic pathway, their combination can better understand the biological effects of stressors in organisms [21]. These perturbed metabolites and proteins are a definite set of molecular biomarkers related to biological effects of stressors [11,12]. Therefore, these two '-omic' techniques provide a great potential in environmental monitoring of environmental stressors, such as pathogens, using corresponding metabolite and protein biomarkers. To our knowledge, no attempt has been made to test the responses induced by bacteria in marine aquaculture animals using a combined proteomic and metabolomic approach.

As a Gram-negative bacterium, V. anguillarum is the dominant pathogen for marine aquaculture animals along the Bohai coast in China. V. anguillarum is an opportunistic pathogen and expresses pathogenicity when its host is injured or immunocompromised [1,22,23]. Micrococcus luteus is a Gram-positive bacterium that can be found in both aquatic and soil environments as well as in aquatic organisms [24]. In M. galloprovincialis, several studies have compared the responses to both Grampositive and Gram-negative bacteria based on the gene expression and functional parameters involved in immune system $[7,10]$. In this study, the proteomic and metabolomic responses were compared in M. galloprovincialis challenged by V. anguillarum and $M$. luteus, respectively. The tissue of hepatopancreas from M. galloprovincialis was used for proteomic and metabolomic analysis, since this organ is an important digestive and immune organ and can accumulate a large number of bacteria due to the filter-feeding habit of invertebrates $[8,25]$. The aim of this work was to illustrate the differential effects induced by these two representative Gram-positive and Gram-negative bacteria in M. galloprovincialis.

\section{Materials and methods}

\subsection{Animals and experimental conditions}

Adult mussels M. galloprovincialis (shell length: $5.5-6.0 \mathrm{~cm}, n=24$ ) were collected in July 2012 from an aquaculture farm (Yantai, China). Animals were transported to the laboratory and acclimatized in aerated natural seawater (salinity 31 PSU) for $10 \mathrm{~d}$. After acclimatization, the animals were randomly separated into four groups (blank, PBS control, M. luteus and V. anguillarum challenges) each containing 6 individuals in $12 \mathrm{~L}$ filtered seawater. The culture seawater was renewed daily. During the acclimation and experimental periods, mussels were kept at $25^{\circ} \mathrm{C}$ under a photoperiod of $12 \mathrm{~h}$ light and $12 \mathrm{~h}$ dark, and fed with the Chlorella vulgaris at a ration of $2 \%$ tissue dry weight daily.

\subsection{Challenge experiment}

For challenge experiment, live V. anguillarum and M. luteus were re-suspended in PBS, respectively. Each mussel of bacteria-challenged groups was injected with V. anguillarum and $\mathrm{M}$. luteus in $50 \mu \mathrm{L}$ PBS (137 mM NaCl, $2.7 \mathrm{mM} \mathrm{KCl}, 10 \mathrm{mM}$ $\mathrm{Na}_{2} \mathrm{HPO}_{4}, 2 \mathrm{mM} \mathrm{KH}_{2} \mathrm{PO}_{4}, \mathrm{pH}$ 7.4) in the adductor muscle with a final concentration of $10^{7} \mathrm{CFU} / \mathrm{mL}$, respectively. It should be 
noted that this concentration of bacteria was used to study the immune responses of $\mathrm{M}$. galloprovincialis and not environmental relevant. The animals in PBS control group were injected with $50 \mu \mathrm{L}$ PBS. The group without any treatment was used as blank group. For injection, each mussel was poked slightly at the edge of the shells. Then the PBS or bacteria solution was injected carefully into the adductor muscle using a syringe. After injections, all the mussels were put back to the tanks and sampled at $24 \mathrm{~h}$ post-injection. Hepatopancreas of each mussel was dissected quickly and flash-frozen in liquid nitrogen, and then stored at $-80^{\circ} \mathrm{C}$ before protein, RNA and metabolite extraction. For further procedures, each treatment consisted of 6 and 3 (2 pooled into 1) replicates for metabolomic and proteomic analysis, respectively.

\subsection{Protein extraction}

Total protein extraction was applied based on Lee et al. [26] and Kirkland et al. [27] with some modifications. Briefly, the tissue of hepatopancreas was homogenized quickly on ice with $1 \mathrm{~mL}$ of Trizol reagent and centrifuged at $12,000 \mathrm{~g}$ for $5 \mathrm{~min}$ at $4{ }^{\circ} \mathrm{C}$. The supernatant was added with $200 \mu \mathrm{L}$ of chloroform before shaking vigorously for $3 \mathrm{~min}$ and precipitating for $3 \mathrm{~min}$. Then the mixture was centrifuged at $12,000 \mathrm{~g}$ for $15 \mathrm{~min}$ at $4{ }^{\circ} \mathrm{C}$ and its upper aqueous layer was discarded. A volume of $300 \mu \mathrm{L}$ of absolute ethyl alcohol was added and the mixture was allowed to stand for $3 \mathrm{~min}$ at room temperature before being centrifuged at $2000 \mathrm{~g}$ for $5 \mathrm{~min}$ at $4{ }^{\circ} \mathrm{C}$. The phenol/ethanol supernatant was precipitated for $30 \mathrm{~min}$ at room temperature by the addition of $750 \mu \mathrm{L}$ of isopropanol prior to centrifugation at $14,000 \mathrm{~g}$ for $10 \mathrm{~min}$ at $4{ }^{\circ} \mathrm{C}$. Pellets obtained were washed with $1 \mathrm{~mL}$ ethanol (v/v $95 \%$ ) and centrifuged at $14000 \mathrm{~g}$ for $10 \mathrm{~min}$ at $4{ }^{\circ} \mathrm{C}$. This procedure was repeated twice. The pellets were solubilized in the lysis buffer (7 M urea; $2 \mathrm{M}$ thiourea; $4 \% \mathrm{~m} / \mathrm{v}$ CHAPS; $65 \mathrm{mM}$ DTT and $0.2 \% \mathrm{w} / \mathrm{v}$ Bio-lyte buffer) and then incubated for $3 \mathrm{~h}$ at room temperature [28]. The homogenate was centrifuged at $15,000 \mathrm{~g}$ for $10 \mathrm{~min}$ and the supernatant was applied to electrophoresis. The total concentrations of proteins were determined by Protein Assay Kit of Tiangen.

\subsection{Metabolite extraction}

Polar metabolites in mussel hepatopancreas tissues $(n=6$ for each treatment) were extracted by the modified extraction protocol as described previously [29,30]. Briefly, the hepatopancreas tissue $(100 \mathrm{mg})$ was homogenized in $400 \mu \mathrm{L}$ of methanol and $85 \mu \mathrm{L}$ of water. Then the mixture was shaken and centrifuged ( $5 \mathrm{~min}, 3000 \mathrm{~g}$, at $4^{\circ} \mathrm{C}$ ), and the supernatant substance was removed. A total of $200 \mu \mathrm{L}$ of chloroform and $440 \mu \mathrm{L}$ of water were added to the supernatant, and the mixture was vortexed and centrifuged again $(10 \mathrm{~min}, 3000 \mathrm{~g}$, $4{ }^{\circ} \mathrm{C}$ ). The methanol/water layer with polar metabolites was transferred to a glass vial and dried in a centrifugal concentrator. The extracts of hepatopancreas were then re-suspended in $600 \mu \mathrm{L}$ of phosphate buffer $\left(100 \mathrm{mM} \mathrm{Na}_{2} \mathrm{HPO}_{4}\right.$ and $\mathrm{NaH}_{2} \mathrm{PO}_{4}$, including $0.5 \mathrm{mM}$ TSP, $\mathrm{pH}$ 7.0) in $\mathrm{D}_{2} \mathrm{O}$. The mixture was vortexed and centrifuged at $3000 \mathrm{~g}$ for $5 \mathrm{~min}$ at $4{ }^{\circ} \mathrm{C}$. The supernatant substance $(550 \mu \mathrm{L})$ was then pipetted into a $5 \mathrm{~mm}$ NMR tube prior to NMR analysis.

\subsection{RNA extraction and quantitation of gene expressions}

Total RNA from the hepatopancreas tissue was isolated following the manufacturer's directions (Invitrogen), and the firststrand cDNA synthesis was carried out according to M-MLV RT Usage information (Promega) using oligo (dT)-adaptor (5'-CTCG AGATCGATGCGGCCGCT17-3') as primer and the DNase I-treated (Promega) total RNA as template. The expressions of the housekeeping genes (Table 1) in M. galloprovincialis hepatopancreas were determined by qRT-PCR, the data were analyzed with geNorm to calculate the expression stability of the genes ( $M$ values) and the optimal number of reference genes required for accurate normalization ( $V$ values) [31]. GeNorm identified $\beta$-actin as the most stable gene, which was lower than the expression stability threshold of 1.5 , then was followed in stability by glyceraldehyde-3-phosphate dehydrogenase, $\alpha$-tubulin, $28 \mathrm{~s}$ rRNA and 18s rRNA. The results showed that the V2/3 value of 0.132 was less than the proposed geNorm cutoff value of 0.15 , which meant that the gene of $\beta$-actin was the most stable gene and was then used as the internal control for gene expression normalization.

Gene-specific primers (Table 2) for selected genes were used to amplify amplicons specific for M. galloprovincialis. The fluorescent real-time quantitative PCR amplifications were carried out in triplicate in a total volume of $20 \mu \mathrm{L}$ containing $10 \mu \mathrm{L}$ of $2 \times$ SYBR Premix Ex Taq ${ }^{\text {TM }}$ (TaKaRa), $0.4 \mu \mathrm{L}$ of $50 \times$ ROX Reference DYE II, $4.8 \mu \mathrm{L}$ DEPC-treated $\mathrm{H}_{2} \mathrm{O}, 0.4 \mu \mathrm{L}$ of each primer, and $4.0 \mu \mathrm{L}$ of 1:20 diluted cDNA. The fluorescent real-time quantitative PCR program was as the following: $50{ }^{\circ} \mathrm{C}$ for $2 \mathrm{~min}$ and $95^{\circ} \mathrm{C}$ for $10 \mathrm{~min}$, followed by 40 cycles of $94{ }^{\circ} \mathrm{C}$ for $15 \mathrm{~s}, 58{ }^{\circ} \mathrm{C}$ for $45 \mathrm{~s}$, and $72{ }^{\circ} \mathrm{C}$ for $30 \mathrm{~s}$. Dissociation curve analysis of amplification products was performed at the end of each PCR to confirm that only one PCR product was amplified and detected. After the PCR program, data were analyzed with the ABI 7500 SDS software (Applied Biosystems). To maintain consistency, the baseline was set automatically by the software. The comparative CT method ( $2^{-\Delta \Lambda C T}$ method) was used to analyze the expression level of the genes [32].

\subsection{Two-dimensional gel electrophoresis}

The first dimension (IEF) was performed using Immobiline Drystrip (24 cm, pH 3-10, linear). One hundred and forty micrograms of proteins to a final volume of $450 \mu \mathrm{L}$ was loaded. Isoelectric focusing gel solution containing $7 \mathrm{M}$ urea, $2 \mathrm{M}$ thiourea, 4\% m/v CHAPS, $65 \mathrm{mM} \mathrm{DTT}, 0.001 \% \mathrm{~m} / \mathrm{v}$ Bromophenol blue and $0.2 \% \mathrm{w} / \mathrm{v}$ Bio-lyte buffer. IEF was conducted at $20{ }^{\circ} \mathrm{C}$ with an Ettan IPGphor3 system for a total of $85,858 \mathrm{~V} \mathrm{~h}$ (active rehydration was carried out at $30 \mathrm{~V}$ for $12 \mathrm{~h}$, followed by $100 \mathrm{~V}$ for $5 \mathrm{~h}, 500 \mathrm{~V}$ for $1 \mathrm{~h}, 1000 \mathrm{~V}$ for $1 \mathrm{~h}$, and a linear increase of voltage to $8000 \mathrm{~V}$ for $11 \mathrm{~h}$ ).

After the first dimension, strips were placed in equilibration buffer (0.05 M Tris-HCl, pH 8.8; $6 \mathrm{M}$ urea; 30\% glycerol; 2\% $\mathrm{w} / \mathrm{v}$ SDS; containing $1 \% \mathrm{w} / \mathrm{v}$ DTT) and were slowly shaken for $15 \mathrm{~min}$. The strips were then incubated for another $15 \mathrm{~min}$ in the equilibration buffer with $2.5 \%(\mathrm{w} / \mathrm{v})$ iodoacetamide without DTT. The second dimension was conducted on $12.5 \%$ SDS-PAGE gels using the Ettan DALTsix system. After electrophoresis, the gels were silver stained by following the method of Mortz and Gharahdaghi $[33,34]$. Images were captured by 
Table 1 - The primer sequences for the determination of housekeeping genes from $\mathbf{M}$. galloprovincialis.

\begin{tabular}{lll}
\multicolumn{1}{c}{ Gene name } & Forward primer $\left(5^{\prime}-3^{\prime}\right)$ & Reverse primer $\left(5^{\prime}-3^{\prime}\right)$ \\
\hline$\beta$-Actin & GCTATCCAGGCCGTACTCT & GCGGTGGTTGTGAATGAG \\
$\alpha$-Tubulin & GACCACCCATACCACCCTT & CTCCGTGAGATCGACATTC \\
18s rRNA & AGAAACGGCTACCACATCC & TGCCCTCCAATAGATCCTC \\
28s rRNA & CCGAGACCGAGGATTGCC & ACCGATTCGCCACTGACCC \\
Glyceraldehyde-3-phosphate dehydrogenase & AGGGTCCAATGAAGGGTG & TTAAGAGCGATGCCAGCT \\
\hline
\end{tabular}

ImageScanner III and spots were quantitatively analyzed by using ImageMaster 2D Platinum 7.0. The abundance of each protein spot was estimated by the percentage volume (\% vol). Only those with significant changes $(>1.5$ folds and $p<0.05)$ based on one-way ANOVA were considered to be differentially expressed proteins.

\subsection{In gel digestion and MS analysis}

In gel digestion was according to Katayama et al. [35]. Protein spots were washed three times with ultrapure water, destained with $25 \mathrm{mmol} / \mathrm{L} \mathrm{NH}_{4} \mathrm{HCO}_{3}$ in $50 \% \mathrm{v} / \mathrm{v}$ acetonitrile at room temperature for $30 \mathrm{~min}$. The gels were dried using $50 \%$ acetonitrile for $30 \mathrm{~min}$ and $100 \%$ acetonitrile for another $30 \mathrm{~min}$. The samples were rehydrated in $10 \mu \mathrm{L}$ of cover solution $\left(0.02 \mathrm{~g} / \mathrm{L} \mathrm{w} / \mathrm{v}\right.$ trypsin, $25 \mathrm{mmol} / \mathrm{L} \mathrm{NH}_{4} \mathrm{HCO}_{3}$ and $10 \%$ acetonitrile) for $30 \mathrm{~min}$, and then covered with the same solution but without trypsin for digestion overnight at $37^{\circ} \mathrm{C}$. The supernatants were extracted with $5 \%$ TFA in $67 \%$ acetonitrile at $37{ }^{\circ} \mathrm{C}$ for $30 \mathrm{~min}$, and then were centrifuged at $5000 \mathrm{~g}$ for $5 \mathrm{~min}$, so the peptide extracts and the supernatant of the gel spot were combined.

After being completely dried the samples were re-suspended with $5 \mu \mathrm{L}$ of $0.1 \%$ TFA followed by mixing in 1:1 ratio with a saturated solution of $\alpha$-cyano-4-hydroxy-trans-cinnamic acid in $50 \%$ acetonitrile [36]. One microliter of mixture was analyzed by an ABI 4800 MALDI-TOF/TOF Plus mass spectrometer (Applied Biosystems, Foster City, USA), data were acquired in a positive MS reflector using a CalMix5 standard to calibrate the instrument (ABI4800 Calibration Mixture). Both the MS and MS/MS data were integrated and processed by using the GPS Explorer V3.6 software (Applied Biosystems, USA) with default parameters. Proteins were successfully identified based on $95 \%$ or higher confidence interval of their scores in the MASCOT V2.4 search engine (Matrix Science Ltd., London, U.K.). Those proteins of the highest scores for protein spots were chosen for biological interpretation in this work (Table S1). The following parameters were used in the search: NCBInr Metazoa (Animals) (2861494 sequences) database; trypsin as the digestion enzyme; one missed cleavage site; partial modifications of cysteine carbamidomethylation and methionine oxidization; no fixed modifications; $0.15 \mathrm{Da}$ for precursor ion tolerance and $0.25 \mathrm{Da}$ for fragment ion tolerance. Individual ion scores $>40$ indicate identity or extensive homology $(p<0.05)$.

\section{8. ${ }^{1} \mathrm{H}$ NMR spectroscopy}

Metabolite extracts of hepatopancreas from mussels were analyzed on a Bruker AV 500 NMR spectrometer performed at $500.18 \mathrm{MHz}$ (at $25^{\circ} \mathrm{C}$ ) as described previously [37]. All ${ }^{1} \mathrm{H}$ NMR spectra were phased, baseline-corrected, and calibrated (TSP at $0.0 \mathrm{ppm}$ ) manually using TopSpin (version 2.1, Bruker).

\subsection{Spectral pre-processing and pattern recognition analysis}

All one dimensional ${ }^{1} \mathrm{H}$ NMR spectra were converted to a data matrix using the custom-written ProMetab software in Matlab version 7.0 (the Mathworks, Natick, MA, USA) [38]. Each spectrum was segmented into bins with a width of $0.005 \mathrm{ppm}$ between 0.2 and $10.0 \mathrm{ppm}$. The bins of residual water peak between 4.70 and 5.20 ppm were excluded from all the NMR spectra. The total spectral area of the remaining bins was normalized to unity to facilitate the comparison between the spectra. All the NMR spectra were generalized log transformed with a transformation parameter $\lambda=1.0 \times 10^{-8}$ to stabilize the variance across the spectral bins and to increase the weightings of the less intense peaks [38]. Data were mean-centered before principal component analysis (PCA) using PLS Toolbox (version 4.0, Eigenvector Research, Manson, WA).

The unsupervised pattern recognition method, principal component analysis (PCA) was used to reduce the dimensionality of the data and summarize the similarities and differences between multiple NMR spectra [39]. The algorithm of this pattern recognition method calculates the highest amount of correlated variation along PC1, with subsequent PCs containing correspondingly smaller amounts of variance. One-way analysis of variance (ANOVA) was conducted on the PC scores from each group to test the statistical significance $(p<0.05)$ of separations. Furthermore, the supervised multivariate data analysis methods, partial least squares discriminant analysis (PLS-DA) and orthogonal projection to latent structure with discriminant analysis (O-PLS-DA), were sequentially carried out to uncover and extract the statistically significant metabolite variations related to bacterial challenges. The results were

Table 2 - Gene names, GI numbers, primers and lengths of amplicons from M. galloprovincialis hepatopancreas ( $n=6$ ).

\begin{tabular}{lcll}
\multicolumn{1}{c}{ Gene name } & GI number & \multicolumn{1}{c}{ Forward primer $\left(5^{\prime}-3^{\prime}\right)$} & \multicolumn{1}{c}{ Reverse primer $\left(5^{\prime}-3^{\prime}\right)$} \\
\hline Nucleoside diphosphate kinase & 223023089 & CTGAACTGACCCATCCTATT & CCTCTTGGTGCATATTGT \\
Mitochondrial ATP synthase & 37650283 & GGCTGTTTATCAAGAGT & AGAGCCATCTCTTTGGTGATTC \\
Glutamine synthetase & 223024040 & CGAACTTCAGCCTTACG & TACCAACCATGACACCCT \\
Cytosolic malate dehydrogenase & 223021440 & CTGTAAATGAAATGGAGGC & TTGCTGGTTAATGGATGGT \\
Small heat shock protein 24.1 & 347545632 & TCACTTTATGGATGACTGGGAGCCT & CGGTCCTTTTCGTTCAACAGTATC \\
Glutathione S-transferase A & 223025344 & AGGATGAATGAGGCTGTGGC & AGGACCTGCGAGATAAGC \\
\hline
\end{tabular}


visualized in terms of score plots to show the classifications and corresponding loadings plots to show the NMR spectral variables contributing to the classifications. The model coefficients were calculated from the coefficients incorporating the weight of the variables in order to enhance interpretability of the model. Then metabolic differences responsible for the classifications between control and bacteria-challenged groups could be detected in the coefficient-coded loadings plots. The coefficient plots were generated by using MATLAB (V7.0, the Mathworks Inc., Natick, USA) with an in-house developed program and were color-coded with absolute value of coefficients ( $\mathrm{r}$ ). A hot color (i.e., red) corresponds to the metabolites being highly positive/ negative significant in discriminating between groups, while a cool color (i.e. blue) corresponds to no significance. The correlation coefficient was determined according to the test for the significance of the Pearson's product-moment correlation coefficient. The validation of the model was conducted using cross validation and the cross-validation parameter $\mathrm{Q}^{2}$ was calculated, and an additional validation method, permutation test (permutation number $=200$ ), was also conducted in order to evaluate the validity of the PLS-DA models. The $\mathrm{R}^{2}$ in the permutated plot described how well the data fit the derived model, whereas $Q^{2}$ describes the predictive ability of the derived model and provides a measure of the model quality. If the maximum value of $\mathrm{Q}^{2} \max$ from the permutation test was smaller than or equal to the $\mathrm{Q}^{2}$ of the real model, the model was regarded as a predictable model. Similarly, the $R^{2}$ value and difference between the $R^{2}$ and $Q^{2}$ were used to evaluate the possibility of over-fitted models [21]. Metabolites were assigned following the tabulated chemical shifts [40] and quantified by using the software, Chenomx (Evaluation Version, Chenomx Inc., Edmonton, Alberta, Canada). The metabolite concentrations were normalized to the mass of hepatopancreas tissue by calculating the concentrations of metabolites in each NMR tube.

\subsection{Statistical analysis}

Metabolite concentrations were tested for normal distribution (Ryan-Joiner's test) and homogeneity of variances (Bartlett's test). All metabolite concentrations were expressed as means \pm standard deviation. One way analysis of variance (ANOVA) with Tukey's test was conducted on the metabolite concentrations from both seawater control (blank) and PBS control groups to test possible metabolic differences induced by PBS in mussel hepatopancreas. Furthermore, one-way ANOVA combined with Tukey's test was performed on metabolite concentrations between PBS control and bacteria-challenged groups, respectively. A $p$ value less than 0.05 was considered statistically significant. The Minitab software (Version 15, Minitab Inc., USA) was used for the statistical analysis.

\section{Results}

\subsection{Proteomic responses in hepatopancreas of} M. galloprovincialis challenged by M. luteus and V. anguillarum

Comparative proteomics was used to determine the proteomic responses in M. galloprovincialis challenged by V. anguillarum and M. luteus, respectively. A total of 25 spots resolved in 2-DE gels were differentially expressed (>1.5 folds, $p<0.05)$. Fig. 1 represented the differential protein spots in hepatopancreas of $M$. galloprovincialis with $M$. luteus and V. anguillarum challenges. In this study, the protein spots observed in all three biological replicates of silver-stained gels were analyzed by a MALDI-TOF/ TOF mass spectrometry and 21 (84\%) proteins were successfully identified. The details of identified proteins including their

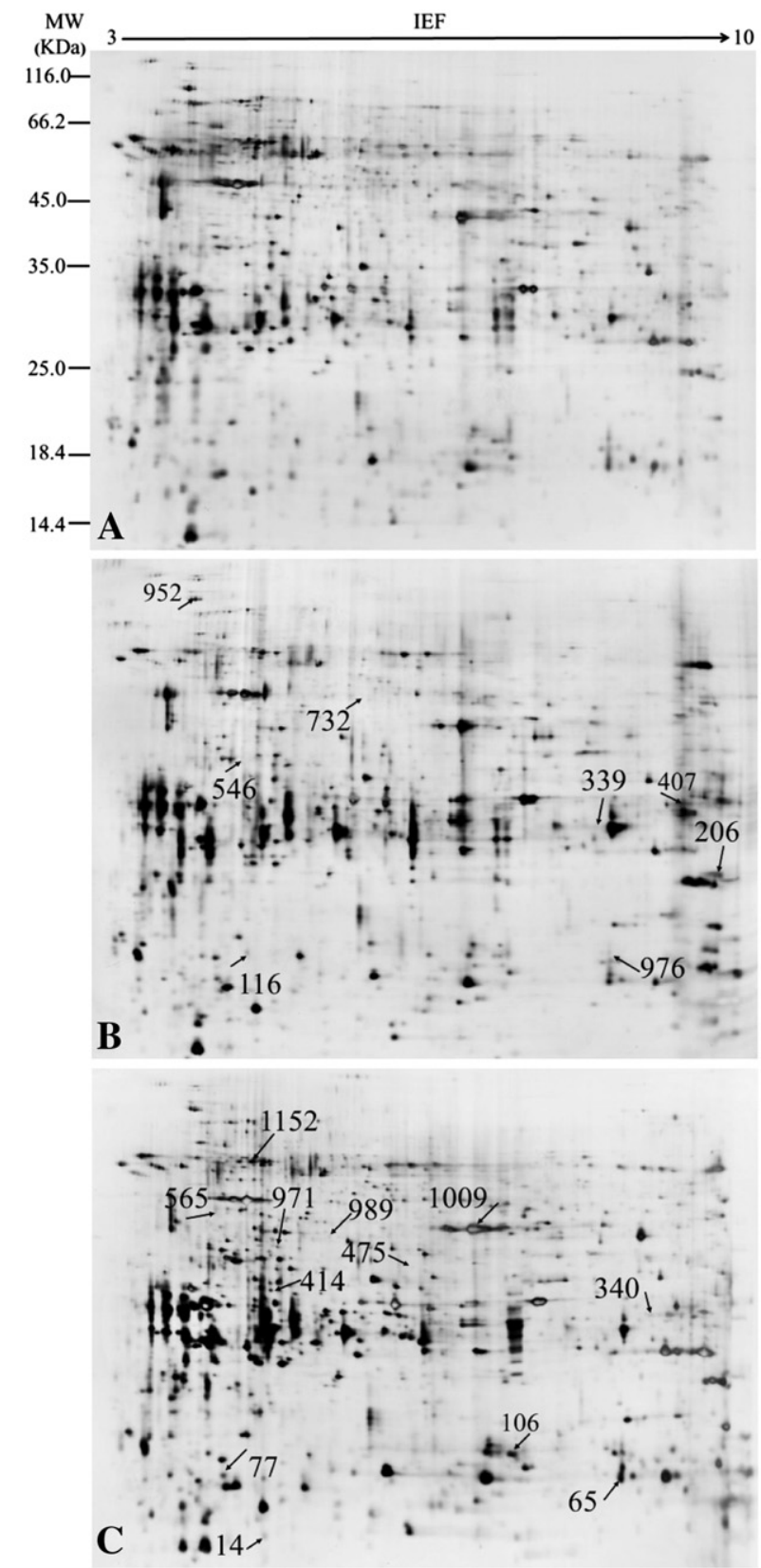

Fig. 1 - Representative 2-DE images of proteins from hepatopancreas of M. galloprovincialis. Proteins were submitted to isoelectric focusing on 3-10 IPG strips $(24 \mathrm{~cm})$ followed by electrophoresis on $12.5 \%$ SDS-PAGE. Gels were silver-stained. Gels (A, B and C) were from (A) PBS control, (B) Micrococcus luteus- and (C) Vibrio anguillarum-challenged groups. The numbered arrows indicate proteins that were identified by MS/MS and are listed in Table 3. 
protein names, accession numbers and other MS data are summarized in the table.

Firstly, we compared the protein spots between blank and PBS control groups. However, no significantly different protein spots were found between these two groups. Therefore, only PBS control group was used for further comparison. In $M$. luteus-challenged group, a total of 11 significantly differential spots were discovered, including 7 up-regulated and 4 down-regulated. These proteins were related to energy and primary metabolisms (V-type proton ATPase subunit, nucleoside diphosphate kinase, proteasome beta 7 subunitlike, cytosolic malate dehydrogenase and arginine kinase), defense system and chaperone (small heat shock protein 24.1 and peptidyl-prolyl cis-trans isomerase), cell growth/division and cytoskeleton (coactosin-like protein and tektin-2) and signaling pathway (putative C1q domain containing protein and $G$ protein B subunit).

Thirteen differentially expressed proteins were observed in V. anguillarum-challenged M. galloprovincialis hepatopancreas, including 6 up-regulated and 7 down-regulated proteins that were basically involved in metabolism (proteasome subunit beta type-1, mitochondrial ATP synthase, glutamine synthetase and arginine kinase), stress and defense (USP-like protein isoform 1, small heat shock protein 24.1, glutathione S-transferase A and $78 \mathrm{kDa}$ glucose regulated protein), cell growth/division and cytoskeleton (coactosin-like protein, F-actincapping protein subunit alpha-like isoform 2 and cytoplasmic actin) and signal transduction (receptor for activated C-kinase and ribosomal protein S7).

\subsection{Metabolomic responses in hepatopancreas of M. galloprovincialis challenged by M. luteus and V. anguillarum}

Fig. 2 shows the representative ${ }^{1} \mathrm{H}$ NMR spectra of hepatopancreas tissue extracts from PBS control, V. anguillarum and M. luteus groups. Several different classes of metabolites were identified in hepatopancreas of M. galloprovincialis, including amino acids (valine, leucine, isoleucine, alanine, threonine, glutamate, asparagine, $\beta$-alanine, glycine, etc.), sugars ( $\alpha, \beta$-glucose), organic osmolytes (betaine, homarine, dimethylglycine, taurine and hypotaurine), intermediates in the Krebs cycle (succinate and fumarate) and energy metabolismrelated metabolites (ATP).

Principal component analysis (PCA) was performed on the NMR spectral datasets of hepatopancreas extracts from blank, PBS control, V. anguillarum- and M. luteus-treated groups. No significant ( $p=0.786$, one way ANOVA on PC scores) separation between blank and PBS control groups was found in score plot (PC1 vs. PC2, data not shown). It confirmed that PBS injection in adductor muscle did not induce significant metabolic changes in mussel hepatopancreas. Then only PBS control group was used in further metabolomic analysis. Obviously, PCA resulted in significant $(p<0.01)$ separations between PBS control, V. anguillarum and M. luteus groups, as shown in Fig. 3. In addition, the significant $(p<0.01)$ separation between $V$. anguillarum- and $M$. luteus-challenged groups was found as well.

Further analysis of O-PLS-DA and one way ANOVA was performed on the NMR spectral data and quantified metabolite concentrations to seek the metabolic biomarkers induced

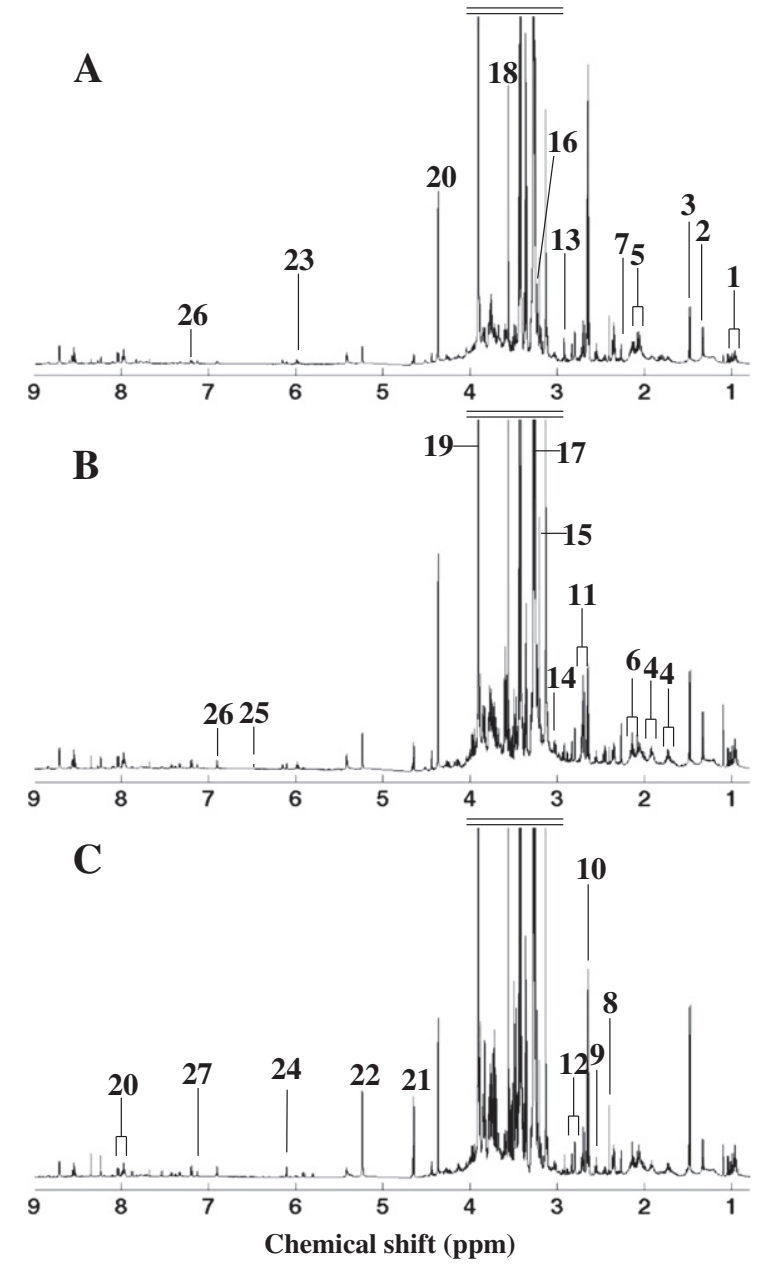

Fig. 2 - Representative 1-dimensional $500 \mathrm{MHz}^{1} \mathrm{H}$ NMR spectra of tissue extracts from hepatopancreas of M. galloprovincialis from (A) PBS control, (B) M. luteus- and (C) V. anguillarum-challenged groups. Keys: (1) branched chain amino acids: valine, leucine and isoleucine,

(2) threonine, (3) alanine, (4) arginine, (5) glutamate, (6) glutamine, (7) acetoacetate, (8) succinate, (9) $\beta$-alanine, (10) hypotaurine, (11) aspartate, (12) asparagine, (13) dimethylglycine, (14) lysine, (15) choline, (16) phosphocholine, (17) taurine, (18) glycine, (19) betaine, (20) homarine, (21) $\beta$-glucose, (22) $\alpha$-glucose, (23) unknown (5.98 ppm), (24) ATP, (25) fumarate, (26) tyrosine and (27) histidine.

by V. anguillarum and M. luteus, respectively (Fig. 4). Clearly, the concentrations of glucose, fumarate and amino acids including valine, leucine, arginine, lysine and tyrosine were significantly $(p<0.05)$ increased in $M$. luteus-challenged mussel samples. The concentrations of ATP and homarine were decreased. Compared to the metabolic biomarkers in M. luteuschallenged group, several metabolites were similarly altered including some amino acids (valine, leucine, lysine, tyrosine and homarine) and ATP. However, elevated succinate and glutamine and depleted aspartate were uniquely detected in V. anguillarumchallenged mussel samples. In addition, arginine and tyrosine were not significantly altered in this group. Especially, fumarate was decreased in V. anguillarum-challenged mussel group, which 


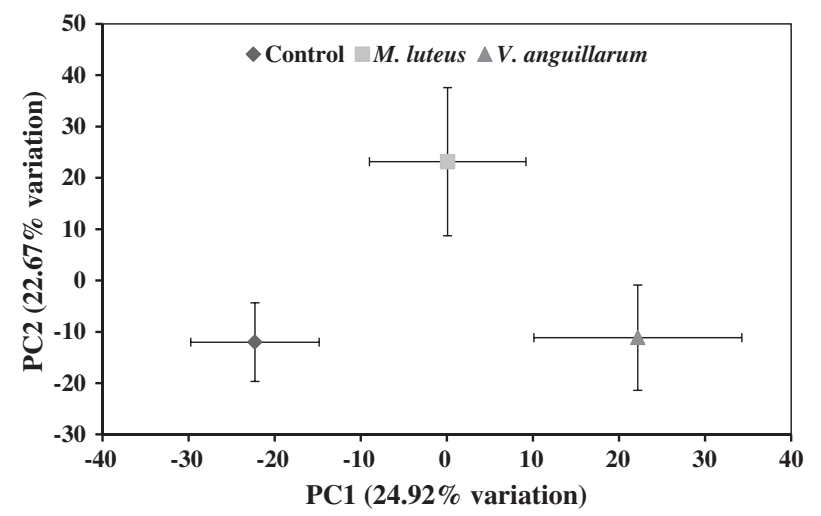

Fig. 3 - Mean principal component analysis (PCA) score plot of PC1 versus PC2 for ${ }^{1} \mathrm{H}$ NMR spectra of tissue extracts from hepatopancreas of $\mathbf{M}$. galloprovincialis from PBS control, M. luteus- and V. anguillarum-challenged groups. The classes were presented as mean \pm standard deviation (as associated standard error) of PC scores for each group of mussel samples.

was contrary to that in M. luteus-challenged mussel samples. Fig. 5 displays the schematic presentation of integrated proteomic and metabolomic responses in hepatopancreas from M. galloprovincialis challenged by M. luteus and V. anguillarum according to Kyoto Encyclopedia of Genes and Genomes (http:// www.genome.jp/kegg/) and Uniprot (http://www.uniprot.org/).
3.3. Correlation between gene expressions and protein abundances

To further verify the results of protein responses and compare the correlation between protein abundances and gene expressions, six representative genes related to altered proteins were quantified using qRT-PCR technique. The results indicated that the levels of the gene expressions had different alteration tendencies with corresponding proteins (Fig. 6).

\section{Discussion}

4.1. Effects of $\mathbf{M}$. luteus and V. anguillarum on the proteome of hepatopancreas in M. galloprovincialis

Approximately 1000 protein spots were resolved in the gels from the hepatopancreas of M. galloprovincialis. Fig. 5A summarized the pathways involved in the response of M. galloprovincialis to $M$. luteus challenge. In $M$. luteus-challenged mussel samples, the responsive proteins (Table 3) related to metabolism were involved in energy and primary metabolisms. Proteasomes play a critical role in ubiquitin-mediated protein degradation through the ubiquitin-proteasome pathway and are involved in cell proliferation, apoptosis and stress responses [41]. He et al. found that the transcription of proteasome in hemocytes was up-regulated in Penaeus japonicus after microbial challenge [42]. Therefore proteasomes were regarded as an essential component defense system of P. japonicus. In our case, the significant
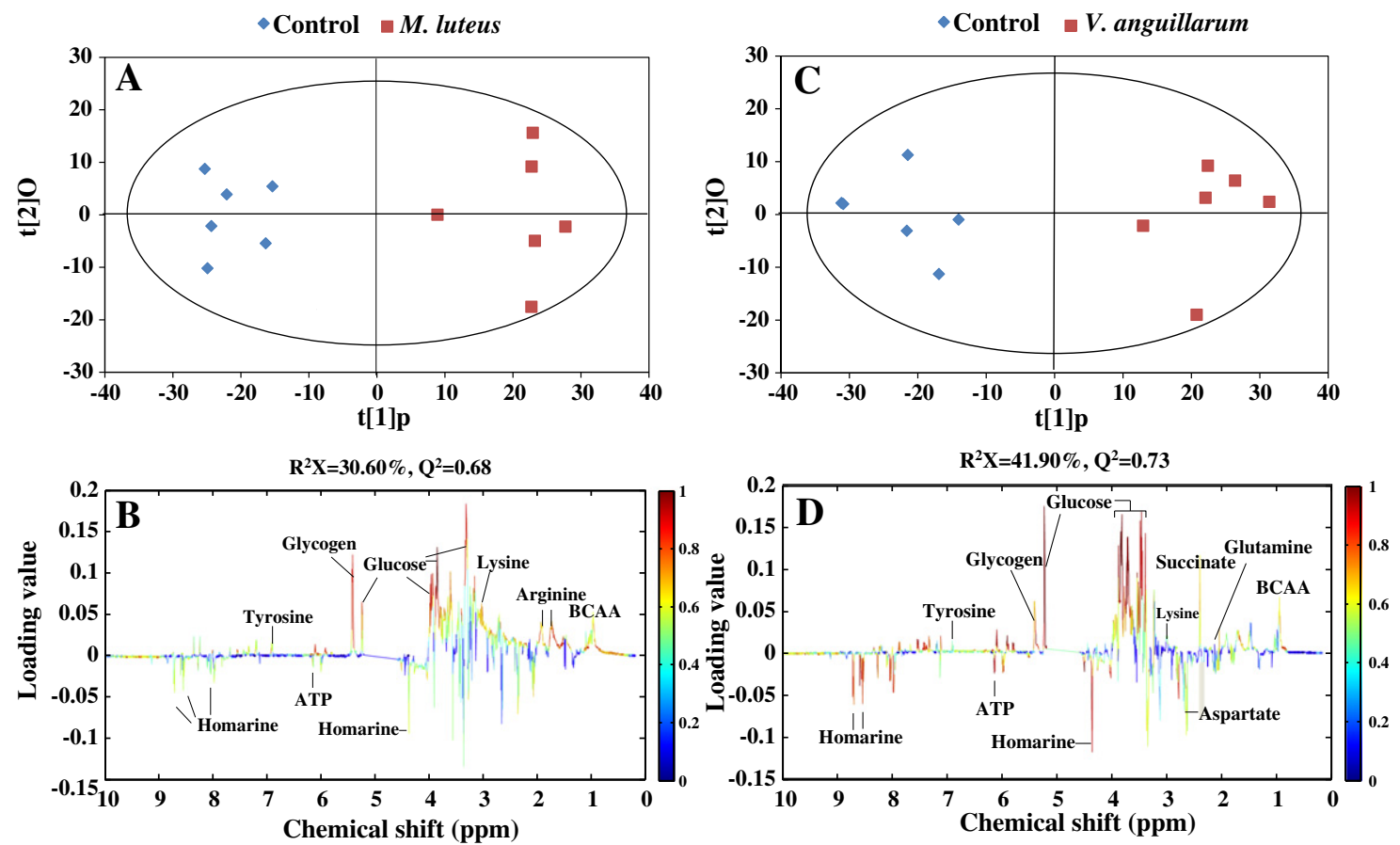

Fig. 4 - OPLS-DA scores derived from ${ }^{1} \mathrm{H}$ NMR spectra of tissue extracts from PBS control ( $)$ and bacteria-challenged groups ( $\square$ ), (A) M. luteus injection and (C) V. anguillarum injection and corresponding coefficient plots (B) and (D). The color map shows the significance of metabolite variations between the two classes (solvent control and bacteria injection). Peaks in the positive direction indicate metabolites that are more abundant in the bacteria-challenged groups. Consequently, metabolites that are more abundant in the control group are presented as peaks in the negative direction. Abbreviations: ATP, adenosine triphosphate; BCAA, branched chain amino acids. 


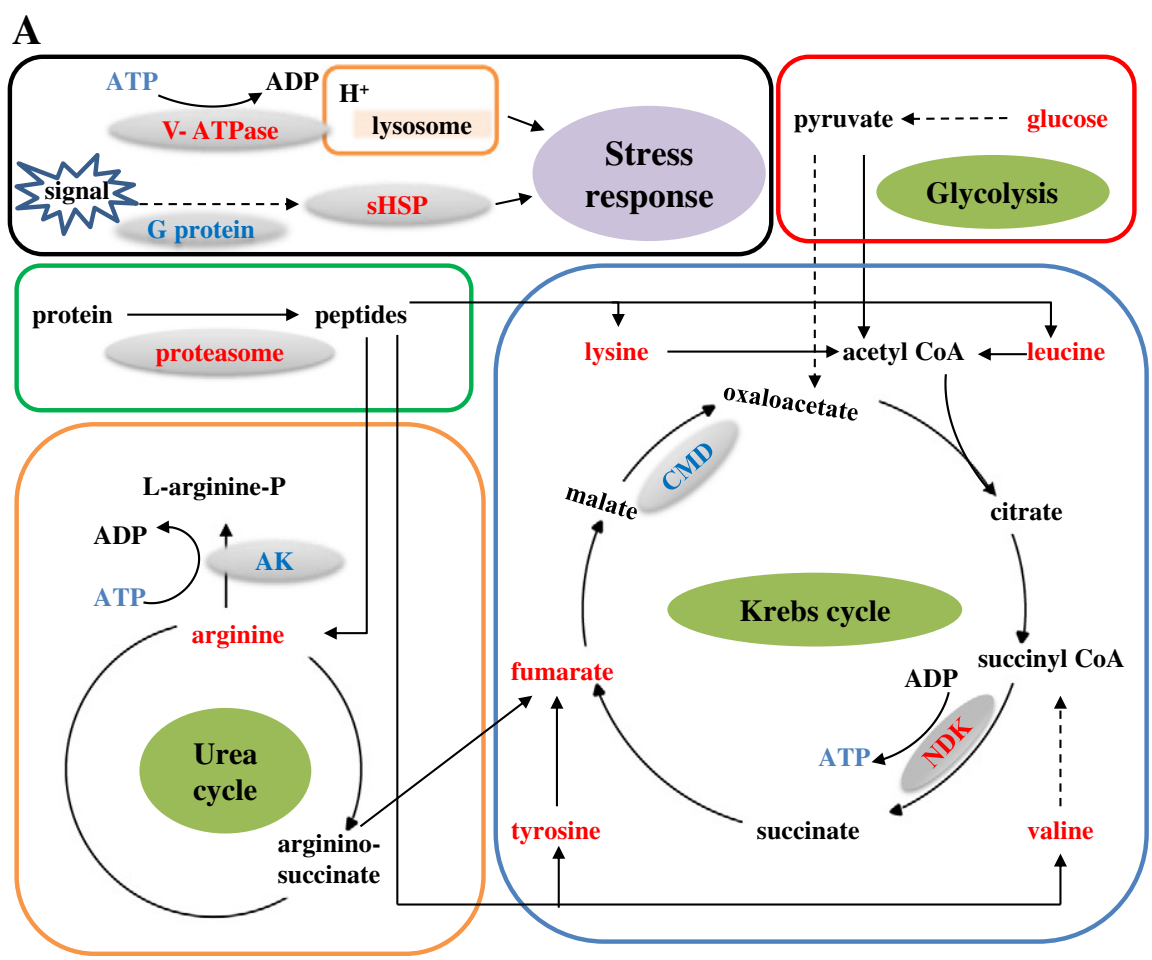

B

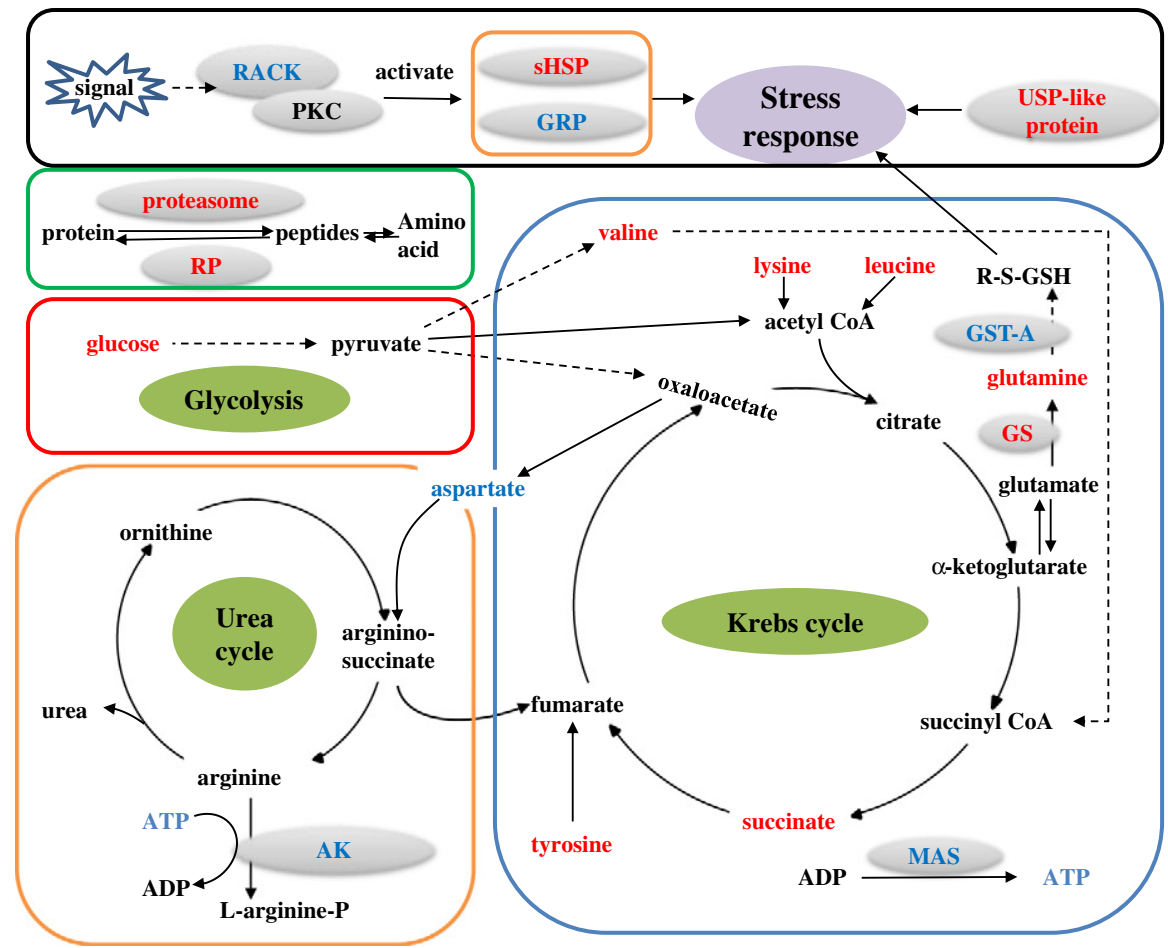

Fig. 5 - Schematic presentation of molecular responsive-mechanisms in hepatopancreas from M. galloprovincialis challenged by M. luteus and V. anguillarum according to Kyoto Encyclopedia of Genes and Genomes (http://www.genome.jp/kegg/) and Uniprot (http://www.uniprot.org). The identified proteins and metabolites were shown by marking the names in red (up-regulated) or blue (down-regulated). Abbreviation: ADP, adenosine diphosphate; AK, arginine Kinase; ATP, adenosine triphosphate; CMD, cytosolic malate dehydrogenase; Gly, glycine; GRP, glucose regulated protein; GS, glutamine synthetase; GST-A, glutathione S-transferase A; MAS, mitochondrial ATP synthase; NDK, nucleoside diphosphate kinase; PKC, protein kinase C; RACK, receptor for activated C-kinase; Ser, serine; sHSP, small heat shock protein; Thr, threonine. 

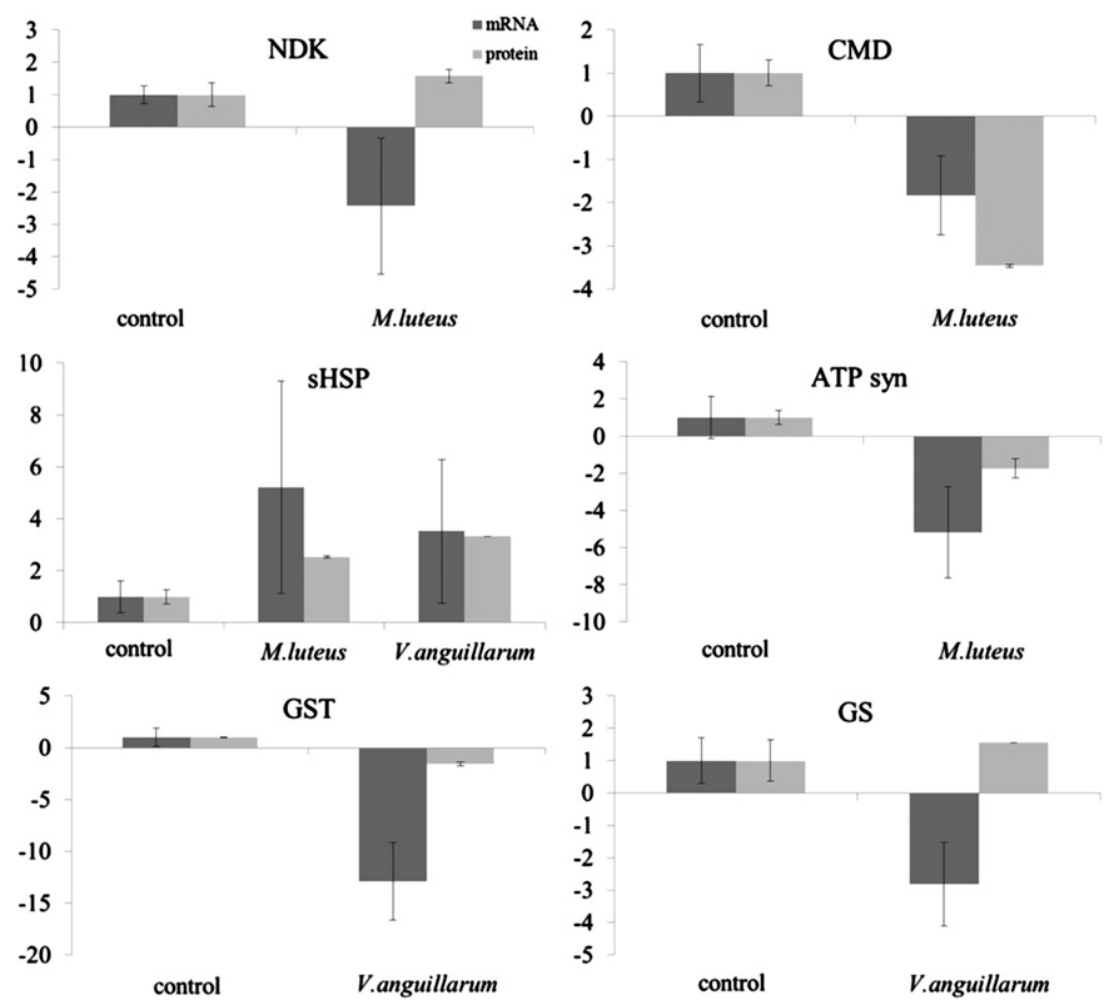

Fig. 6 - Comparison of six genes at the mRNA and protein levels in the mussel M. galloprovincialis induced by M. luteus and V. anguillarum. The mRNA and protein values of the ratio of treatment group to the control are plotted. Abbreviations: ATP syn: mitochondrial ATP synthase; CMD: cytosolic malate dehydrogenase; GS: glutamine synthetase; GST: glutathione S-transferase A; NDK, nucleoside diphosphate kinase; sHSP: small heat shock protein 24.1.

up-regulation of proteasome beta 7 subunit-like might imply that this protein contributed to the defense system of M. galloprovincialis. Cytosolic malate dehydrogenase is a NADrelated enzyme in the Krebs cycle. It is usually involved in the transfer of reducing equivalents from cytosol to mitochondria and regulates energy metabolism in organisms [43]. Arginine kinase belongs to the class of phosphagen kinases catalyzing the reversible transphosphorylation between phosphoarginine and ADP [44]. In addition, ATPases are a class of enzymes catalyzing the decomposition of ATP into ADP and a free phosphate ion [45]. This dephosphorylation process releases energy and can decrease the amount of ATP. Therefore the down-regulation of arginine kinase and up-regulation of ATPase meant the disturbance in energy metabolism and resulted in the depletion of ATP, which was clearly observed in the metabolic profiles from M. luteus-challenged mussel samples (Table 2). In the hepatopancreas of Fenneropenaeus chinensis infected by white spot syndrome virus, however, arginine kinase was significantly up-regulated, which probably indicated the differential responsive mechanisms between bacteria and virus in marine invertebrates [46]. Nucleoside diphosphate kinases (NDKs) are enzymes that catalyze the exchange of phosphate groups between various nucleoside diphosphates [45]. For example, NDKs can convert guanosine triphosphate (GTP) to ATP in TCA cycle. Since M. luteus challenge led to the decrease of ATP, the NDK was probably mobilized (up-regulated) in mussel hepatopancreas to produce more ATP to compensate the consumption of ATP. As shown in Fig. 5A, the up-regulation of NDK and ATPase could result in the depletion of ATP, which was confirmed by the decreased ATP in hepatopancreas of M. luteus-challenged M. galloprovincialis (Table 4). The consistency between proteomic and metabolomic biomarkers suggested that proteomics and metabolomics could validate one another using the corresponding biomarkers involved in the same metabolic pathway.

Peptidyl-prolyl cis-trans isomerases (PPIase) can catalyze the cis-trans isomerization of peptide bonds on the amino-terminal side of proline [47]. It has been thought to be essential for protein folding during protein synthesis in the cell [47]. The up-regulation of PPIase might imply the disturbance in protein synthesis in M. luteus-challenged mussel samples. Small heat shock proteins (sHSPs) usually execute two main defensive functions including cytoskeleton stabilization and anti-apoptotic activity [48]. Hereby, the increased level of two sHSP 24.1 in mussel samples indicated potential cellular injury and (or) apoptosis caused by M. luteus challenge. Both coactosin-like protein and tektin-2 are cytoskeleton proteins $[49,50]$. The significant alteration in these two proteins implied the cellular injury induced by $M$. luteus challenge in M. galloprovincialis. G proteins are involved in signaling pathways [51]. Recent studies demonstrated that G proteins could be critical for the stress responses [51]. C1q domain containing protein is reported to function as a pattern recognition receptor (PRR) in mollusk innate immunity [52]. One C1q domain containing protein was the most remarkably up-regulated protein in M. luteus-challenged mussels, which suggested the disturbance in immune system of M. luteus injection. 
Table 3-List of protein spots which were differentially expressed in M. galloprovincialis hepatopancreas induced by M. luteus and V. anguillarum.

\begin{tabular}{|c|c|c|c|c|c|c|c|c|c|}
\hline Spot ID ${ }^{b}$ & Protein name & Species & $\begin{array}{l}\text { Accession } \\
\text { number }\end{array}$ & $\mathrm{MW} / \mathrm{kDa}^{\mathrm{d}}$ & pI & $\begin{array}{l}\text { Protein } \\
\text { score }^{e}\end{array}$ & $\mathrm{PN}^{\mathrm{f}}$ & $\mathrm{SC}^{\mathrm{g}}$ & $\begin{array}{c}\text { Fold } \\
\text { change }^{h}\end{array}$ \\
\hline \multicolumn{10}{|c|}{ Energy and primary metabolism } \\
\hline 14 & $\begin{array}{l}\text { V-type proton ATPase subunit } \\
\text { F-like }\end{array}$ & Strongylocentrotus purpuratus & 212814234 & 23806 & 4.91 & 164 & 3 & 12 & $1.75^{\mathrm{a}}$ \\
\hline 106 & Nucleoside diphosphate kinase & Ornithodoros parkeri & 149286936 & 17311 & 7.3 & 64 & 2 & 7 & $1.58^{\mathrm{a}}$ \\
\hline 234 & Proteasome subunit beta type- 1 & Crassostrea gigas & 238647170 & 29015 & 7.83 & 148 & 10 & 61 & $1.51^{a}$ \\
\hline 265 & Mitochondrial ATP synthase & Haliotis discus discus & 37650283 & 14109 & 4.48 & 146 & 3 & 38 & $-1.74^{a}$ \\
\hline 340 & Proteasome beta 7 subunit-like & Saccoglossus kowaleuskii & 238644949 & 26592 & 8.58 & 185 & 4 & 29 & $1.61^{\mathrm{a}}$ \\
\hline 609 & Glutamine synthetase & Strongylocentrotus purpuratus & 47551039 & 42024 & 5.75 & 247 & 5 & 17 & $1.55^{\mathrm{a}}$ \\
\hline 989 & Cytosolic malate dehydrogenase & Mytilus trossulus & 73656269 & 36599 & 5.52 & 210 & 8 & 28 & $-1.83^{a}$ \\
\hline 1009 & Arginine kinase & Aplysia kurodai & 223022743 & 26905 & 6.95 & 471 & 8 & 34 & $\begin{array}{l}-1.84^{\mathrm{a}} \\
-1.93^{\mathrm{a}}\end{array}$ \\
\hline \multicolumn{10}{|c|}{ Defense and chaperones } \\
\hline 65 & Peptidyl-prolyl cis-trans isomerase & Blattella germanica & 1706258 & 18095 & 8.25 & 89 & 1 & 9 & $1.51^{\mathrm{a}}$ \\
\hline 72 & USP-like protein isoform 1 & Crassostrea ariakensis & 223024010 & 28778 & 7.61 & 62 & 2 & 13 & $1.64^{\mathrm{a}}$ \\
\hline 414 & Small heat shock protein 24.1 & Mytilus galloprovincialis & 347545633 & 28691 & 5.11 & 95 & 2 & 8 & $\begin{array}{l}2.53^{\mathrm{a}} \\
3.32^{\mathrm{a}}\end{array}$ \\
\hline 480 & Glutathione S-transferase A & Crassostrea gigas & 223025344 & 19416 & 5.16 & 53 & 4 & 26 & $-1.56^{a}$ \\
\hline 952 & $78 \mathrm{kDa}$ glucose regulated protein & Crassostrea gigas & 238639954 & 26710 & 4.38 & 384 & 4 & 10 & $-2.11^{\mathrm{a}}$ \\
\hline \multicolumn{10}{|c|}{ Cell growth/division and cytoskeleton } \\
\hline 77 & Coactosin-like protein & Eisenia fetida & 238638414 & 21604 & 4.55 & 604 & 5 & 25 & $\begin{array}{l}1.58^{\mathrm{a}} \\
1.92^{\mathrm{a}}\end{array}$ \\
\hline 492 & $\begin{array}{l}\text { F-actin-capping protein subunit } \\
\text { alpha-like isoform } 2\end{array}$ & Apis mellifera & 66508517 & 32953 & 5.97 & 113 & 3 & 12 & $-1.90^{a}$ \\
\hline 979 & Cytoplasmic actin & Tegillarca granosa & 306489668 & 41952 & 4.88 & 62 & 6 & 9 & $-2.64^{\mathrm{a}}$ \\
\hline 1152 & Tektin-2 & Crassostrea gigas & 145888591 & 35038 & 5.01 & 365 & 5 & 18 & $-1.65^{a}$ \\
\hline \multicolumn{10}{|c|}{ Signal transduction } \\
\hline 475 & Receptor for activated C-kinase & Pinctada fucata & 238643150 & 25540 & 6.46 & 92 & 2 & 14 & $-1.89^{a}$ \\
\hline 565 & $\begin{array}{l}\text { Putative C1q domain containing } \\
\text { protein }\end{array}$ & Mytilus galloprovincialis & 238643093 & 20948 & 4.71 & 54 & 3 & 45 & $3.27^{\mathrm{a}}$ \\
\hline 971 & G protein B subunit & Ostrea edulis & 375073754 & 38004 & 4.12 & 286 & 6 & 26 & $-1.90^{\mathrm{a}}$ \\
\hline 182 & Ribosomal protein S7 & Argopecten irradians & 22758886 & 22402 & 6.57 & 99 & 2 & 10 & $1.58^{a}$ \\
\hline $\begin{array}{l}\text { a Identifica } \\
\text { groups, anc } \\
\text { b Assigned } \\
\text { c Database } \\
\text { d Experime } \\
\text { e Mascot s } \\
\text { f Number } \\
\text { g Sequence } \\
\text { h Fold cha }\end{array}$ & $\begin{array}{l}\text { ation of differentially expressed pro } \\
\text { d between control and Vibrio anguil } \\
\text { spot ID as indicated in Fig. } 3 \text {. } \\
\text { accession numbers after searchin } \\
\text { ental mass. } \\
\text { core reported. } \\
\text { of peptide sequences. } \\
\text { e coverage. } \\
\text { nges with significances }(>1.5 \text { folds }\end{array}$ & $\begin{array}{l}\text { larum-challenged groups, resp } \\
\text { g against the NCBInr database }\end{array}$ & $\begin{array}{l}\text { patopancreas } \\
\text { ectively. }\end{array}$ & between cont & trol an & d Micrococ & cus lut & eus-ch & allenged \\
\hline
\end{tabular}

V. anguillarum is one of the most common pathogens to marine bivalves. The immune responses of marine bivalves to V. anguillarum challenges have been extensively investigated at molecular levels [7,10]. Fig. 5B summarized the proteomic and metabolomic responses involved in the pathways. In the hepatopancreas of mussels challenged by V. anguillarum, three of the thirteen identified proteins including arginine kinase, sHSP 24.1 and coactosin-like protein were altered similarly to those in M. luteus-challenged mussel samples. However, other ten proteins were uniquely expressed in V. anguillarumchallenged mussel samples. These proteomic biomarkers implied the differential effects of V. anguillarum to M. galloprovincialis compared with those proteomic biomarkers induced by M. luteus. The proteasomes are involved in the proteasomal degradation pathway and can respond to environmental stresses [53]. The significant up-regulation of proteasome subunit beta type-1 indicated the defensive response of $M$. galloprovincialis to V. anguillarum challenge, which was similarly indicated by the up-regulated proteasome beta 7 subunit-like in M. luteuschallenged mussel samples, resulting in elevated amino acids such as lysine, leucine and valine (Fig. 5). The down-regulated mitochondrial ATP synthase should be related to the disturbed energy metabolism combined with the up-regulated arginine kinase and resulted in the decrease of ATP, which was observed in the metabolic profiles from V. anguillarum-challenged mussel samples (Fig. 5B). Glutamine synthetase plays an essential role in the metabolism of nitrogen by catalyzing glutamate into glutamine (Fig. 5B). The up-regulation of glutamine synthetase could lead to the increase of glutamine and decrease of glutamate and ATP, which was detected in the metabolic 


\begin{tabular}{|c|c|c|c|}
\hline Metabolites & $\begin{array}{c}\text { Chemical } \\
\text { shift (ppm, } \\
\text { multiplicity) }\end{array}$ & M. luteus & V. anguillarum \\
\hline Valine & $1.05(d)$ & $1.58^{\mathrm{b}}$ & $1.58^{\mathrm{b}}$ \\
\hline Isoleucine & $1.00(d)$ & No change & No change \\
\hline Leucine & $0.94(t)$ & $2.17^{\mathrm{c}}$ & $2.22^{\mathrm{c}}$ \\
\hline Threonine & $1.34(\mathrm{~d})$ & No change & No change \\
\hline Alanine & $1.48(\mathrm{~d})$ & No change & No change \\
\hline Arginine & $1.70(\mathrm{~m})$ & $1.79^{\mathrm{b}}$ & No change \\
\hline Glutamate & $2.05(\mathrm{~m})$ & No change & No change \\
\hline Glutamine & $2.14(\mathrm{~m})$ & No change & $1.71^{\mathrm{b}}$ \\
\hline Acetoacetate & $2.26(\mathrm{~s})$ & No change & No change \\
\hline Succinate & $2.41(\mathrm{~s})$ & No change & $2.75^{c}$ \\
\hline$\beta$-Alanine & $2.55(t)$ & No change & No change \\
\hline Hypotaurine & $2.66(t)$ & No change & No change \\
\hline Aspartate & $2.68(\mathrm{ABX})$ & No change & $-1.30^{b}$ \\
\hline Asparagine & 2.85 (ABX) & No change & No change \\
\hline Dimethylglycine & $2.91(\mathrm{~s})$ & No change & No change \\
\hline Lysine & $3.03(t)$ & $1.90^{\mathrm{c}}$ & $1.49^{\mathrm{b}}$ \\
\hline Choline & $3.21(\mathrm{~s})$ & No change & No change \\
\hline Phosphocholine & $3.22(\mathrm{~s})$ & No change & No change \\
\hline Taurine & $3.27(t)$ & No change & No change \\
\hline Betaine & $3.91(\mathrm{~s})$ & No change & No change \\
\hline Glycine & $3.56(\mathrm{~s})$ & No change & No change \\
\hline Glucose & $\begin{array}{l}4.64(d) \\
5.24(d)\end{array}$ & $1.62^{\mathrm{b}}$ & $3.15^{\mathrm{c}}$ \\
\hline Homarine & $4.37(\mathrm{~s})$ & $1.18^{\mathrm{b}}$ & $-1.44^{c}$ \\
\hline ATP & $6.15(\mathrm{~d})$ & $-2.27^{b}$ & $10.0^{c}$ \\
\hline Fumarate & $6.52(\mathrm{~s})$ & $1.44^{\mathrm{b}}$ & No change \\
\hline Tyrosine & $6.91(\mathrm{~d})$ & $2.10^{c}$ & $1.70^{c}$ \\
\hline Histidine & $7.12(\mathrm{~s})$ & No change & No change \\
\hline
\end{tabular}

${ }^{\mathrm{a}} \mathrm{s}=$ singlet $\mathrm{d}=$ doublet $\mathrm{t}=$ triplet $\mathrm{m}=$ multiplet, $\mathrm{ABX}=$ complex multiplet involving 2 protons ( $\mathrm{A}$ and $\mathrm{B}$ ) and a heavy atom $(\mathrm{X})$.

${ }^{\mathrm{b}}$ Fold changes with significances $(p<0.05)$ between control and bacteria-challenged M. galloprovincialis samples were determined by one-way ANOVA with Tukey's test.

c Fold changes with significances $(p<0.01)$ between control and bacteria-challenged $M$. galloprovincialis samples were determined by one-way ANOVA with Tukey's test.

profiles from V. anguillarum-challenged mussel samples (Table 4, Fig. 5B).

The ubiquitin-specific protease-like (USP-like) protein is involved in protein homeostasis [54]. In our case, the upregulated USP-like protein isoform 1 implied the disturbance in protein homeostasis caused V. anguillarum injection in mussel. Glutathione S-transferases (GSTs) are related to the reduction of reactive oxygen species (ROS) production. Canesi et al. reported that the activity of GST activity was decreased in hepatopancreas of $M$. galloprovincialis to $V$. anguillarum injection [8], which was consistently observed in this work. One glucose regulated protein (GRP78) was similarly downregulated to the glutathione S-transferase in V. anguillarumchallenged mussel samples. GRP78 is a stress protein belonging to the $70 \mathrm{kDa}$ heat shock protein family that can be used to protect cells from stresses [55]. These two altered proteins could be reflected in stronger oxidative stress conditions in the hepatopancreas of mussels challenged with V. anguillarum [8]. Both cytoplasmic actin and F-actin-capping proteins are cytoskeleton-associated proteins that were down-regulated in V. anguillarum-challenged mussel samples. In a previous study, V. anguillarum challenge induced a significant downregulation of actin in hepatopancreas of Zhikong scallop Chlamys farreri [56]. Since the cytoskeleton is involved in multiple functions, such as the maintenance of cell shape and intracellular organization, the alterations of these two cytoskeleton-associated proteins demonstrated the cellular injury caused by V. anguillarum injection. Receptor for activated C-kinase (RACK) is involved in signal transduction, RNA processing and cell cycle processing [57]. Ribosomal proteins perform the crucial function of protein biosynthesis. Both RACK and ribosomal proteins have been recognized as immunogenic proteins [58]. Obviously, the altered RACK and ribosomal protein S7 demonstrated the immune stress in hepatopancreas of mussel challenged by V. anguillarum.

\subsection{Effects of $\mathbf{M}$. luteus and $\mathbf{V}$. anguillarum on the metabolome of hepatopancreas in M. galloprovincialis}

As shown in Fig. 3, the significant $(p<0.01)$ separations between PBS control, V. anguillarum and M. luteus groups meant that there were significant metabolic differences between PBS control and bacteria-challenged groups. Moreover, the significant $(p<0.01)$ separation between V. anguillarum and M. luteus groups demonstrated that these two bacteria induced different biological effects in mussel hepatopancreas.

In both M. luteus- and V. anguillarum-challenged mussel samples, some amino acids including valine, leucine, arginine, lysine and tyrosine were significantly increased. As it is known, organisms can continue cellular energy production during stress via the mitochondrial oxidation of amino acids in Krebs cycle (Fig. 5). This catabolic period of amino acids is usually accompanied by the degradation of proteins in the proteasomal degradation pathway, as indicated by the up-regulated proteasomes, which was observed in both M. luteus- and V. anguillarum-challenged mussel samples. Hereby, the elevated amino acids might be related to a reduced energy demand together with the elevated glucose (enhanced gluconeogenesis) and depleted ATP in M. luteuschallenged group. The consistency between metabolic biomarkers (amino acids, glucose and ATP) and protein biomarkers (proteasomes, ATP synthase and NDK) confirmed the disturbance in energy metabolism induced by both $M$. luteus and V. anguillarum in mussel hepatopancreas (Fig. 5). The increase in fumarate was another indicator of disturbed energy metabolism in $\mathrm{M}$. luteus-challenged mussel samples. The osmolyte, homarine, was significantly decreased in M. luteus-challenged mussel samples. This might imply the disturbances in osmotic regulation induced by $M$. luteus in mussel hepatopancreas [59].

For the V. anguillarum-challenged mussel group, the intermediate in the Krebs cycle, succinate was significantly elevated and aspartate was significantly depleted in hepatopancreas tissue samples. In one possible metabolic pathway, aspartate could be substantially converted into succinate with no detectable enrichment of other compounds under anoxic conditions in mollusk resulting in the decreased aspartate and increased succinate [60]. Therefore the 
decreased aspartate and increased succinate meant the enhanced anaerobiosis in mussel hepatopancreas challenged by $\mathrm{V}$. anguillarum. In addition, the significant increase of glutamine confirmed the up-regulated glutamine synthetase, as mentioned above. Homarine is a known organic osmolyte in marine mollusks.

\subsection{Correlation between gene expressions and protein abundances}

To further evaluate the correlation between gene expression and protein abundances, the expressions of six genes corresponding to (NDK, mitochondrial ATP synthase, glutamine synthetase, cytosolic malate dehydrogenase, sHSP 24.1 and GST A) in M. galloprovincialis were quantified to explore the correlation between protein and corresponding mRNA expression levels. However, the results indicated that mRNA expressions did not correlate well with the protein abundances (Fig. 6). The disparity between mRNA and corresponding protein expressions was not surprising [61], since mRNA expression means the tendency of the corresponding encoded protein which does not always happen due to the posttranscriptional and posttranslational modifications $[61,62]$.

In summary, the molecular responses induced by bacteria, $M$. luteus and $V$. anguillarum, were investigated at protein and metabolite levels in hepatopancreas of mussel M. galloprovincialis. The metabolic and proteomic biomarkers suggested that these two bacteria injections could induce oxidative stress, disturbances in osmotic regulation and energy metabolism, cellular injury in mussels. Although these two bacteria induced similar effects in hepatopancreas of M. galloprovincialis, the differentiations between $M$. luteus and V. anguillarum were clearly observed from the proteomic and metabolomic profiles. Especially, some uniquely and more remarkably altered metabolic biomarkers (glutamine, succinate, aspartate, glucose, ATP, homarine and tyrosine) demonstrated that V. anguillarum could cause more severe disturbances in osmotic regulation and energy metabolism. In addition, some metabolic biomarkers, ATP and glutamine, were confirmed by related proteins including arginine kinase, ATP synthase and nucleoside diphosphate kinase. This study demonstrated that proteomics and metabolomics could partially validate one another and their combination could provide an insightful view into the effects of environmental pathogens to the marine mussel M. galloprovincialis.

\section{Acknowledgments}

This work was supported by the 100 Talents Program of the Chinese Academy of Sciences and the Key Deployment Program of Chinese Academy of Sciences (KZZD-EW-14-03).

\section{Appendix A. Supplementary data}

Supporting information. Details of proteins with one or multiple identifications (Table S1). Supplementary data to this article can be found online at http://dx.doi.org/10.1016/j. jprot.2013.09.001.

\section{R E F E R E N C E S}

[1] Tubiash HS, Colwell RR, Sakazaki R. Marine vibrios associated with bacillary necrosis, a disease of larval and juvenile bivalve mollusks. J Bacteriol 1970;103:271-2.

[2] Yang S, Wang Y, Dong S. Progress of research on vibriosis in marine cultured fish (in Chinese with English abstract). Mar Fish Res 2005;26:75-83.

[3] Canesi L, Gavioli M, Pruzzo C, Gallo G. Bacteria-hemocyte interactions and phagocytosis in marine bivalves. Microsc Res Tech 2002;57:469-76.

[4] Pruzzo C, Gallo G, Canesi L. Persistence of vibrios in marine bivalves: the role of interactions with hemolymph components. Environ Microbiol 2005;7:761-72.

[5] Ciacci C, Barmo C, Gallo G, Maisano M, Cappello T, Agata A, et al. Effects of sublethal, environmentally relevant concentrations of hexavalent chromium in the gills of Mytilus galloprovincialis. Aquat Toxicol 2012;120-121:109-18.

[6] Li A, Ma J, Cao J, McCarron P. Toxins in mussels (Mytilus galloprovincialis) associated with diarrhetic shellfish poisoning episodes in China. Toxicon 2012;60:420-5.

[7] Costa MM, Prado-Alvarez M, Gestal C, Li H, Roch P, Novoa B, et al. Functional and molecular immune response of Mediterranean mussel (Mytilus galloprovincialis) haemocytes against pathogen-associated molecular patterns and bacteria. Fish Shellfish Immunol 2009;26:515-23.

[8] Canesi L, Barmo C, Fabbri R, Ciacci C, Vergani L, Roch P, et al. Effects of vibrio challenge on digestive gland biomarkers and antioxidant gene expression in Mytilus galloprovincialis. Comp Biochem Physiol C 2010;152:399-406.

[9] Cellura C, Toubiana M, Parrinello N, Roch P. HSP70 gene expression in Mytilus galloprovincialis hemocytes is triggered by moderate heat shock and Vibrio anguillarum, but not by V. splendidus or Micrococcus lysodeikticus. Dev Comp Immunol 2006;30:984-97.

[10] Li H, Parisi MG, Toubiana M, Cammarata M, Roch P. Lysozyme gene expression and hemocyte behaviour in the Mediterranean mussel, Mytilus galloprovincialis, after injection of various bacteria or temperature stresses. Fish Shellfish Immunol 2008;25:143-52.

[11] Santos EM, Ball JS, Williams TD, Wu H, Ortega F, van Aerle R, et al. Identifying health impacts of exposure to copper using transcriptomics and metabolomics in a fish model. Environ Sci Technol 2010;44:820-6.

[12] Fu Z, Zhang L, Liu X, Zhang Y, Zhang Q Li X, et al. Comparative proteomic analysis of the sun- and freeze-dried earthworm Eisenia fetida with differentially thrombolytic activities. J Proteomics 2013;27:1-14.

[13] Li Z, Wu H, Zhang X, Li X, Liao P, Li W, et al. Investigation on the acute biochemical effects of light rare earths (lanthanum and cerium) by NMR-based metabonomic approaches. Chem J Chin Univ 2006;27:438-42.

[14] Anderson NL, Anderson NG. Proteome and proteomics: new technologies, new concepts, and new words. Electrophoresis 1998;19:1853-61.

[15] Kingtong S, Kellner K, Bernay B, Goux D, Sourdaine P, Berthelin $\mathrm{CH}$. Proteomic identification of protein associated to mature spermatozoa in the Pacific oyster Crassostrea gigas. J Proteomics 2013;26:81-91.

[16] Lemos MFL, Soares AMVM, Correia AC, Esteves AC. Proteins in ecotoxicology - how, why and why not? Proteomics 2010;10:873-87.

[17] Lindon JC, Nicholson JK, Everett JR. NMR spectroscopy of biofluid. Ann Rep NMR Spectros, 38; 1999 1-88. 
[18] Feng J, Zhao J, Hao F, Chen C, Bhakoo K, Tang H. NMR-based metabonomics analyses of the effects of ultrasmall superparamagnetic particles of iron oxide (USPIO) on macrophage metabolism. J Nanopart Res 2011;13:2049-62.

[19] Wu H, Zhang X, Li X, Li Z, Wu Y, Pei F. Comparison of metabolic profiles from serum from hepatotoxin-treated rats by nuclear-magnetic-resonance-spectroscopy-based metabonomic analysis. Anal Biochem 2005;340:99-105.

[20] Pedras MSC, Zheng QA. Metabolic responses of Thellungiella halophila/salsuginea to biotic and abiotic stresses: metabolite profiles and quantitative analyses. Phytochemistry 2010;71:581-9.

[21] Zhang H, Ding L, Fang X, Shi Z, Zhang Y, Chen H, et al. Biological responses to perfluorododecanoic acid exposure in rat kidneys as determined by integrated proteomic and metabonomic studies. PLoS One 2011;6:e20862.

[22] Brown C, Losee E. Observations on natural and indued epizootics of vibriosis in Crassostrea virginica larvae. J Invertebr Pathol 1992;31:41-7.

[23] Deng H, Sui XL, Wang ZS. Primary study on vibrios of the Pacific oyster, Crassostrea gigas (in Chinese). Fish Sci 1992;11:1-4.

[24] Spanggaard B, Huber I, Nielsen J, Sick EB, Pipper CB, Martinussen T, et al. The probiotic potential against vibriosis of the indigenous microflora of rainbow trout. Environ Microbiol 2001;3:755-65.

[25] Du J, Zhu H, Liu P, Chen J, Xiu Y, Yao W, et al. Immune responses and gene expression in hepatopancreas from Macrobrachium rosenbergii challenged by a novel pathogen spiroplasma MR-1008. Fish Shellfish Immunol 2013;34:315-23.

[26] Lee SC, Chan J, Clement MV, Pervaiz S. Functional proteomics of resveratrol-induced colon cancer cell apoptosis: caspase-6-mediated cleavage of lamin A is a major signaling loop. Proteomics 2006;6:2386-94.

[27] Kirkland PA, Busby J, Stevens Jr S, Maupin-Furlow JA. Trizol-based method for sample preparation and isoelectric focusing of halophilic proteins. Anal Biochem 2006;351:254-9.

[28] Tullius MV, Phillips NJ, Scheffler NK, Samuels NM, Munson RS, Hansen EJ, et al. The lbgAB gene cluster of Haemophilus ducreyi encodes $\alpha \beta$-1, 4-galactosyltransferase and an $\alpha-1,6$-DD-heptosyltransferase involved in lipooligosaccharide biosynthesis. Infect Immun 2002;70:2853-61.

[29] Wu H, Southam AD, Hines A, Viant MR. High throughput tissue extraction protocol for NMR and mass spectrometry based metabolomics. Anal Biochem 2008;372:204-12.

[30] Lin CY, Wu H, Tjeerdema RS, Viant MR. Evaluation of metabolite extraction strategies from tissue samples using NMR metabolomics. Metabolomics 2007;3:55-67.

[31] Dang W, Sun L. Determination of internal controls for quantitative real time RT-PCR analysis of the effect of Edwardsiella tarda infection on gene expression in turbot (Scophthalmus maximus). Fish Shellfish Immunol 2011;30:720-8.

[32] Livak KJ, Schmittgen TD. Analysis of relative gene expression data using real-time quantitative PCR and the 2(-Delta Delta C(T)) method. Methods 2001;25:402-8.

[33] Mortz E, Krogh TN, Vorum H, Gorg A. Improved silver staining protocols for high sensitivity protein identification using matrix-assisted laser desorption/ionization-time of flight analysis. Proteomics 2001;1:1359-63.

[34] Gharahdaghi F, Weinberg CR, Meagher DA, Mische SM. Mass spectrometric identification of proteins from silver-stained polyacrylamide gel: a method for the removal of silver ions to enhance sensitivity. Electrophoresis 1999;20:601-5.

[35] Katayama H, Nagasu T, Oda Y. Improvement of in-gel digestion protocol for peptide mass fingerprinting by matrix-assisted laser desorption/ionization time-of-flight mass spectrometry. Rapid Commun Mass Spectrom 2001;15:1416-21.
[36] Shevchenko A, Wilm M, Vorm O, Mann M. Mass spectrometric sequencing of proteins from silver-stained polyacrylamide gels. Anal Biochem 1996;68:850-8.

[37] Liu X, Zhang L, You L, Yu J, Zhao J, Li L, et al. Differential toxicological effects induced by mercury in gills from three pedigrees of Manila clam Ruditapes philippinarum by NMR-based metabolomics. Ecotoxicology 2011;20:177-86.

[38] Parsons HM, Ludwig C, Gunther UL, Viant M. Improved classification accuracy in 1- and 2-dimensional NMR metabolomics data using the variance stabilising generalised logarithm transformation. BMC Bioinformatics 2007;8:234.

[39] Xu L. Methods of Chemometrics. Beijing: Science Press; 2004 221-7.

[40] Fan WMT. Metabolite profiling by one- and two-dimensional NMR analysis of complex mixtures. Prog Nucl Magn Reson Spectrosc 1996;28:161-219.

[41] Zhang W, Wei Q. Calcineurin stimulates the expression of inflammatory factors in RAW 264.7 cells by interacting with proteasome subunit alpha type 6 . Biochem Biophys Res Commun 2011;407:668-73.

[42] He N, Liu H, Xu X. Identification of genes involved in the response of haemocytes of Penaeus japonicus by suppression subtractive hybridization (SSH) following microbial challenge. Fish Shellfish Immunol 2004;17:121-8.

[43] Landsperger WJ, Harris BG. NAD ${ }^{+}$-malic enzyme regulatory properties of the enzyme from Ascaris suum. J Biol Chem 1976;251:3599-602.

[44] Alonso GD, Pereira CA, Remedi MS, Paveto MC, Cochella L, Ivaldi MS, et al. Arginine kinase of the flagellate protozoa Trypanosoma cruzi. Regulation of its expression and catalytic activity. FEBS Lett 2011;498:22-5.

[45] Leyva JA, Bianchet MA, Amzel LM. Understanding ATP synthesis: structure and mechanism of the F1-ATPase (review). Mol Membr Biol 2003;20:27-33.

[46] Chai Y, Yu S, Zhao X, Zhu Q, Wang J. Comparative proteomic profiles of the hepatopancreas in Fenneropenaeus chinensis response to white spot syndrome virus. Fish Shellfish Immunol 2010;29:480-6.

[47] Gothel SF, Marahiel MA. Peptidylprolyl cis-trans isomerases, a superfamily of ubiquitous folding catalysts. Cell Mol Life Sci 1999;55:423-36.

[48] Fontaine JM, Rest JS, Welsh MJ, Benndorf R. The sperm outer dense fiber protein is the 10th member of the superfamily of mammalian small stress proteins. Cell Stress Chaperones 2003;8:62-9.

[49] de Hostos EL, Bradtke B, Lottspeich F, Gerisch G. Coactosin, a $17 \mathrm{kDa}$ F-actin binding protein from Dictyostelium discoideum. Cell Motil Cytoskeleton 1993;26:181-91.

[50] Linck RW, Amos LA, Amos WB. Localization of tektin filaments in microtubules of sea urchin sperm flagella by immuno-electron microscopy. J Cell Biol 1985;100:126-35.

[51] Clapham DE, Neer EJ. New roles for G-protein beta-gamma dimers in transmembrane signalling. Nature 1993;365:403-6.

[52] Zhang H, Song L, Li C, Zhao J, Wang H, Qiu L, et al. A novel C1q-domain-containing protein from Zhikong scallop Chlamys farreri with lipopolysaccharide binding activity. Fish Shellfish Immunol 2008;25:281-9.

[53] Aiken CT, Kaake RM, Wang X, Huang L. Oxidative stress-mediated regulation of proteasome complexes. Mol Cell Proteomics 2011;10(5) [R110.006924].

[54] Sanogo YO, Hankison S, Band M, Obregon A, Bell AM. Brain transcriptomic response of threespine sticklebacks to cues of a predator. Brain Behav Evol 2011;77:270-85.

[55] Lee AS. Mammalian stress response: induction of the glucose-regulated protein family. Curr Opin Cell Biol 1992;4:267-73.

[56] Huan P, Wang H, Liu B. Comparative proteomic analysis of challenged Zhikong scallop (Chlamys farreri): a new insight 
into the anti-vibrio immune response of marine bivalves. Fish Shellfish Immunol 2011;31:1186-92.

[57] Hermanto U, Zong CS, Li W, Wang LH. RACK1, an insulin-like growth factor I (IGF-I) receptor-interacting protein, modulates IGF-independent integrin signaling and promotes cell spreading and contact with extracellular matrix. Mol Cell Biol 2002;22:2345-65.

[58] Ruszczyk A, Joerink M, Guldenaar C, Hermsen T, Savelkoul HF, Wiegertjes GF. cDNA expression library screening and identification of two novel antigens: ubiquitin and receptor for activated C kinase (RACK) homologue, of the fish parasite Trypanosoma carassii. Fish Shellfish Immunol 2008;25:84-90.

[59] Viant MR, Rosenblum ES, Tjeerdema RS. NMR-based metabolomics: a powerful approach for characterizing the effects of environmental stressors on organism health. Environ Sci Technol 2003;37:4982-9.

[60] Graham RA, Ellington WR. Phosphorus nuclear magnetic resonance studies of energy metabolism in molluscan tissues: intracellular $\mathrm{pH}$ change and the qualitative nature of anaerobic end products. Physiol Biochem Zool 1985;58:478-90.

[61] Wang X, Chang L, Sun Z, Zhang Y. Comparative proteomic analysis of differentially expressed proteins in the earthworm Eisenia fetida during Escherichia coli O157:H7 stress. J Proteome Res 2010;9:6547-60.

[62] Yan SP, Zhang QY, Tang ZC, Su WA, Sun WN. Comparative proteomics analysis provides new insights into chilling stress responses in rice. Mol Cell Proteomics 2006;5:484-96. 